\title{
Circulating IGF1 and IGF2 and SNP genotypes in men and pregnant and non-pregnant women
}

\section{K L Gatford, G K Heinemann, S D Thompson, J V Zhang, S Buckberry, J A Owens, G A Dekker, C T Roberts and on behalf of the SCOPE Consortium}

School of Paediatrics and Reproductive Health, Robinson Research Institute, University of Adelaide, Adelaide, South Australia 5005, Australia

\author{
Correspondence \\ should be addressed \\ to C T Roberts \\ Email \\ claire.roberts@ \\ adelaide.edu.au
}

\begin{abstract}
Circulating IGFs are important regulators of prenatal and postnatal growth, and of metabolism and pregnancy, and change with sex, age and pregnancy. Single-nucleotide polymorphisms (SNPs) in genes coding for these hormones associate with circulating abundance of IGF1 and IGF2 in non-pregnant adults and children, but whether this occurs in pregnancy is unknown. We therefore investigated associations of plasma IGF1 and IGF2 with age and genotype at candidate SNPs previously associated with circulating IGF1, IGF2 or methylation of the INS-IGF2-H19 locus in men $(n=134)$, non-pregnant women $(n=74)$ and women at 15 weeks of gestation $(n=98)$. Plasma IGF1 concentrations decreased with age $(P<0.001)$ and plasma IGF1 and IGF2 concentrations were lower in pregnant women than in non-pregnant women or men (each $P<0.001$ ). SNP genotypes in the INS-IGF2-H19 locus were associated with plasma IGF1 (IGF2 rs680, IGF2 rs1004446 and IGF2 rs3741204) and IGF2 (IGF2 rs1004446, IGF2 rs3741204 and H19 rs217727). In single SNP models, effects of IGF2 rs680 were similar between groups, with higher plasma IGF1 concentrations in individuals with the GG genotype when compared with GA $(P=0.016)$, or combined GA and AA genotypes $(P=0.003)$. SNPs in the IGF2 gene associated with IGF1 or IGF2 were in linkage disequilibrium, hence these associations could reflect other genotype variations within this region or be due to changes in INS-IGF2-H19 methylation previously associated with some of these variants. As IGF1 in early pregnancy promotes placental differentiation and function, lower IGF1 concentrations in pregnant women carrying IGF2 rs680 A alleles may affect placental development and/or risk of pregnancy complications.
\end{abstract}

\section{Introduction}

The insulin-like growth factors (IGFs), IGF1 and IGF2, are important regulators of placental and foetal development, as well as postnatal growth and metabolism. In humans, circulating IGF1 peaks in adolescence and then falls with age, whereas IGF2 concentrations remain fairly stable after puberty (1). The pubertal peak in plasma IGF1 occurs 1-2 years earlier in girls than in boys, resulting in higher circulating IGF1 concentrations in girls than in boys through adolescence (2, 3). Plasma IGF1 concentrations are fairly similar in men and women $(2,4)$ but slightly lower circulating IGF1 concentration in adult women than in men has been reported in large studies $(3,5)$. Plasma IGF2 is similar in adolescent and young adult men and women $(6,7)$, but

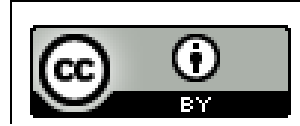


whether IGF2 remains similar between sexes throughout ageing is unknown.

IGF abundance is also altered by pregnancy. Variable changes in circulating IGF1 during the first two trimesters of human pregnancy have been reported, with modest increases of $25-40 \%$ compared with non-pregnant women (8) or a gradual overall rise with increasing gestation and highly variable concentrations between women in crosssectional studies $(9,10)$. Longitudinal studies have shown stable concentrations from early pregnancy (8-10 weeks) until after 30 weeks of gestation $(11,12)$, or decreased concentrations in the first trimester up until 24 weeks of gestation compared with pre-conception $(13,14,15)$. All these studies agree that maternal circulating IGF1 is 45-200\% higher in the third trimester when compared with non-pregnant women, early pregnancy or preconception $(8,9,10,11,12,13,14,15,16)$. Fewer studies have characterised circulating IGF2 abundance throughout pregnancy. Gargosky et al. (8) reported much higher plasma IGF2 concentrations than IGF1 concentrations in pooled plasma from pregnant women, measured by RIA after HPLC separation of samples to completely remove IGF-binding proteins. IGF2 concentrations were highly variable between different stages of pregnancy, but as these were analysed in pooled samples it is difficult to draw conclusions about changes across pregnancy (8). In an early cross-sectional study, plasma IGF2 concentrations were higher in women in the third trimester when compared with the first trimester of pregnancy and decreased post partum (10). Two longitudinal studies each measuring IGF2 by RIA after acid-ethanol extraction reported decreases of $\sim 10 \%$ in plasma IGF 2 in the first trimester compared with concentrations in the same women before pregnancy $(14,15)$. As pregnancy progressed, plasma IGF2 returned to pre-conception concentrations (14) or increased to $\sim 10 \%$ above pre-conception concentrations (15). In addition to effects on maternal metabolism, IGFs act as endocrine signals to enhance placental function and foetal growth (reviewed by (17)). We have previously directly demonstrated the endocrine actions of maternal IGFs to enhance placental differentiation and function and hence foetal growth in the guinea pig $(18,19,20)$. Consistent with this, late pregnancy maternal circulating IGF1 concentration is reduced in human pregnancies complicated by IUGR compared with those with normally grown neonates $(11,21)$.

Genetic variation also impacts the IGF axis and circulating IGF1 and IGF2 differ between individuals according to their genotype at single-nucleotide polymorphisms (SNPs) in the genes for IGF1, IGF2 and the IGF1 receptor $(I G F 1 R)$. Within the IGF1 locus, rs12579108 is weakly associated with plasma IGF1 in children in combination with other SNPs (22), while the rare C allele of the IGF1 rs7965399 SNP was associated with increased plasma IGF1 concentrations in older women but not with plasma IGF1 concentrations in other populations $(23,24,25)$. Consistent with a positive effect of the IGF1 rs7965399 C allele on IGF1, this allele was also associated with a trend towards higher IGF1 concentration in breast tumours (26). Circulating IGF1 is also associated with genotype at the IGF1R rs2229765 SNP, which is predicted to regulate alternative splicing of $\operatorname{IGF1R}(27)$. The AA genotype at this SNP predicts lower plasma IGF1 concentrations in adult men and women compared with GG individuals in most $(28,29,30)$, but not all, studies $(31,32)$, with lower plasma IGF1 concentrations also reported in AG heterozygotes (28). The AA genotype also predicts increased longevity $(28,29,30)$, and shorter male adult height (33), consistent with decreased IGF1 action in these individuals, as absence of IGF1 signalling through IGF1R reduces postnatal growth (34), and IGF1 deficiency predicts longevity (35).

IGF2 is located in an imprinted gene cluster on chromosome 11p15.5 (Fig. 1), containing genes for H19, $I G F 2$, insulin (INS), tyrosine hydroxylase $(T H)$ and an antisense IGF2 gene overlapping with IGF2 (IGF2-AS). The $H 19$ long non-coding RNA in this cluster is maternally expressed and this imprinting appears to remain stable with age $(36,37)$. IGF2 and $H 19$ are reciprocally imprinted during early development and, in foetal, placental and many adult tissues, IGF2 is paternally expressed from the P0, P2, P3 and P4 promoters $(36,37,38)$. P1 promoter transcripts of IGF2 are expressed from both parental alleles and IGF2 is expressed bi-allelically in liver from older infants and adults, where imprinting of IGF2 is not closely co-regulated with that of $H 19(36,37)$. We have recently reported discordant imprinting of IGF2 and H19 in first trimester human placenta at 6 weeks of gestation, where expression of IGF2 is mono-allelic but imprinting of $H 19$ is highly variable (39). Individuals with BeckwithWiedemann syndrome and loss of imprinting at this locus, who therefore express maternal and paternal IGF2 alleles, often have pre- and postnatal overgrowth, suggesting increased IGF2 availability (reviewed by (40)). This suggests that SNPs associated with altered DNA methylation at this locus may also regulate circulating IGF2. Indeed, plasma IGF2 concentrations have previously been associated with genotype at two SNPs associated with INS-IGF2-H19 methylation. Specifically, IGF2 rs680 and H19 rs217727 SNPs strongly correlate with methylation of

This work is licensed under a Creative Commons Attribution 3.0 Unported License. 

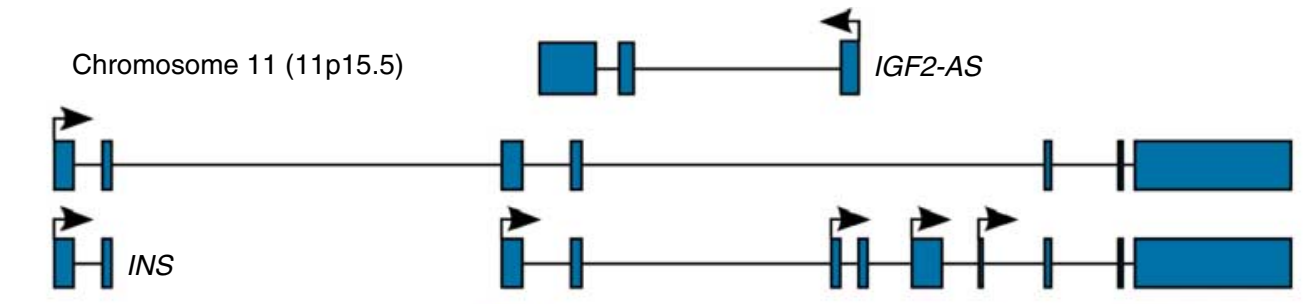

INS-IGF2

$\square$ DMR

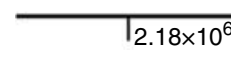

rs1004446 rs3741204

$12.16 \times 10^{6}$

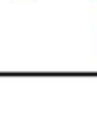

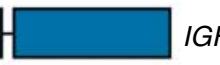

IGF2

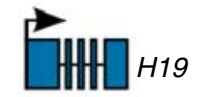

\section{Figure 1}

Schematic of the Homo sapiens INS-IGF2-H19 locus. Exons are represented as blue boxes with intronic regions between exons as black lines. Black arrows above exons show transcription start sites and direction of transcription. Orange boxes indicate the approximate location of differentially methylated regions (DMRs). The $x$-axis shows genomic

multiple CpG sites within the IGF2 and H19 differentially methylated regions respectively (41). Circulating IGF2 concentrations were higher in individuals homozygous for the A allele at IGF2 rs680 (ApaI), compared with those homozygous for the $G$ allele in middle-aged men (42). The A allele is also part of a haplotype of four SNPs that are positively associated with IGF2 protein content of placentas collected at term (43). Others found no effect of IGF2 rs680 on plasma IGF2 concentrations in studies of middle-aged to elderly men and women $(44,45,46)$. Conversely, the IGF2 rs680 G allele was associated with higher IGF2 mRNA expression in leukocytes (47). Neonatal IGF2 rs680 A alleles were associated with lower birth weight than $G$ alleles in Brazilian and Japanese populations $(48,49)$. By contrast, maternal (50) or neonatal $(43,50,51)$ IGF2 rs680 genotypes were not associated with birth weight in Caucasian populations. A paternally inherited foetal A allele at IGF2 rs680 was, however, associated with higher maternal circulating glucose post-challenge at 27-29 weeks of gestation (43), consistent with an effect of this allele on maternal adaptation to pregnancy. Only one study has investigated differences in circulating IGF2 with the H19 rs217727 SNP. The presence of one or more $\mathrm{T}$ alleles at $H 19$ rs 217727 in women was positively associated with birth size and cord blood IGF2 in their neonates, with the TT genotype relatively rare $(<5 \%)$ in mothers and newborns (52). Methylation of the INS-IGF2-H19 locus also differs according to genotype at IGF2 rs1004446 (41) and IGF2 rs3741204. IGF2 rs3741204 is located within the P3 promoter of IGF2 within the DMRO region that affects imprinting of IGF2 and H19. The A allele is observed in two different four SNP haplotypes associated with either position in base pairs for human chromosome 11 and the position of singlenucleotide polymorphisms (SNPs, denoted by rs number) investigated in this study. This representation is based on human reference genome hg19, dbSNP 138 and RefSeq transcripts.

increased or decreased methylation of the INS-IGF2-H19 locus in Beckwith-Wiedemann syndrome (53). Associations of IGF2 rs1004446 and IGF2 rs3741204 with circulating IGF2 have not been reported as yet.

Although relationships between SNP genotype and circulating IGFs have been previously investigated in non-pregnant subjects, no studies to date have reported their associations in pregnant women, when circulating IGF concentrations regulate placental and foetal growth and development (17). We therefore investigated whether relationships between circulating IGF1 and IGF2 abundance and SNP genotypes previously associated with circulating IGFs (IGF1 rs12579108, IGF1 rs7965399, IGF1R rs2229765, IGF2 rs680 and $H 19$ rs217727) and/or methylation of the INS-IGF2-H19 locus (IGF2 rs680, IGF2 rs1004446, IGF2 rs3741204 and H19 rs217727) differ among men, pregnant women and non-pregnant women.

\section{Materials and methods}

\section{Study populations and sample collection}

Circulating IGFs and genotype data from Caucasian subjects within two independent studies are included in the present analysis. Non-pregnant women were from a general population cohort and pregnant women from a subset of the Adelaide Screening for Pregnancy Endpoints (SCOPE) cohort, who had a normal pregnancy outcome, as described below, while male subjects were from the general population or partners of the pregnant women (Table 1).

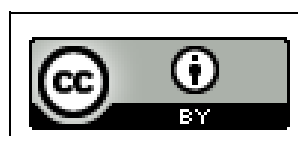

This work is licensed under a Creative Commons Attribution 3.0 Unported License. 
Table 1 Subject characteristics. This study includes only Caucasian individuals with data for circulating IGFs and genotype. Subject characteristics are expressed as median (range).

\begin{tabular}{lcc}
\hline & & Men \\
\cline { 1 - 2 } Number & & 134 \\
Age (years) & & $25.0(17-59)$ \\
Body weight $(\mathrm{kg})$ & & $82.0(55.0-133.1)$ \\
Height $(\mathrm{m})$ & $1.81(1.64-1.96)$ \\
BMI $\left(\mathrm{kg} / \mathrm{m}^{2}\right)$ & $24.7(18.0-37.0)$ \\
\hline
\end{tabular}

Healthy, non-pregnant adults were recruited from the general population in Adelaide, South Australia, and gave informed consent for participation in the study. Inclusion criteria were age (18-60 years) and not taking regular medication other than the oral contraceptive pill. Firstdegree (siblings, parent-child) and second-degree relatives (cousins) were excluded. Ethics approval for this work was given by the University of Adelaide Human Research Ethics Committee (H-021-2005).

Pregnant women and their partners were recruited from a nested case-control study within the Adelaide SCOPE cohort, an international prospective cohort study recruiting patients in Australia, New Zealand (ACTRN12607000551493, Australian and New Zealand Clinical Trials Registry), UK and Ireland, which aims to predict and prevent the major complications of late pregnancy (54). Women who were nulliparous with a singleton pregnancy at $<15$ weeks of completed gestation and with no more than two previous terminations of pregnancy or miscarriages were recruited into the Adelaide cohort after providing written informed consent at the Lyell McEwin Hospital antenatal clinic (Elizabeth Vale, SA, Australia). This study includes only women who had an uncomplicated pregnancy, defined as women who remained normotensive $(<140 \mathrm{mmHg}$ systolic and/or $<90 \mathrm{mmHg}$ diastolic prior to labour), showed no proteinuria, delivered a live born baby who was not small for gestational age after 37 weeks of completed gestation and had no other signs of pregnancy complications. The pregnant women in this study were the 98 women in whom genotype and circulating IGF data were available, from a cohort of 133 control women with normal pregnancy outcomes, BMI-matched to pregnant women who later developed preeclampsia or gestational hypertension (55) or gestational diabetes or who delivered before 37 weeks of completed gestation (preterm) or a small-for-gestational-age infant. Ethics approval for this work was given by the Ethics of Human Research Committee, Central Northern Adelaide Health Service (REC 1712/5/2008).

\begin{tabular}{c} 
Non-pregnant women \\
\hline 74 \\
$23.5(18-51)$ \\
$64.0(43.0-100.0)$ \\
$1.66(1.53-1.78)$ \\
$23.1(17.7-39.5)$ \\
\hline
\end{tabular}

\begin{tabular}{c} 
Pregnant women \\
\hline 98 \\
$23.0(14-39)$ \\
$72.5(44.8-125.1)$ \\
$1.65(1.49-1.82)$ \\
$26.8(17.7-44.8)$
\end{tabular}

Non-fasting blood samples were collected by venepuncture from women at 15 weeks of gestation, and their partners sometimes, during the women's pregnancy, and from general population subjects. Samples were collected into EDTA tubes and placed on ice, before centrifugation at $2400 \boldsymbol{g}$ for $10 \mathrm{~min}$ at $4{ }^{\circ} \mathrm{C}$. Plasma and buffy coats were harvested and stored at $-80^{\circ} \mathrm{C}$ for subsequent analyses.

\section{Plasma IGF1 and IGF2 analyses}

Concentrations of plasma IGF1 and IGF2 were measured by RIA after separation of IGFs and IGFBPs by size-exclusion HPLC under acidic conditions $(8,56)$. Four fractions of eluate (fraction 1, containing IGFBPs; fraction 2, inter-peak; fraction 3, containing IGFs and fraction 4, post-peak) were routinely collected for each acidified plasma sample, using collection times based on elution times of ${ }^{125}$ I-IGF1 and IGF immunoreactivity. Recovery of ${ }^{125}$ I-IGF1 was $88.0 \pm 1.1 \%$ for five HPLC runs of human plasma. Samples were assayed in triplicate. Plasma IGF1 concentrations were measured by analysis of neutralised HPLC fraction 3, in an RIA specific for IGF1, using a rabbit polyclonal antibody to human IGF1 (GroPep, Adelaide, SA, Australia). Plasma IGF2 concentrations were measured by analysis of HPLC fraction 3 in an RIA specific for IGF2 (57), using a mouse MAB against rat IGF2, which has $100 \%$ cross-reactivity with human IGF2 and $<10 \%$ cross-reactivity with human IGF1 (anti-IGF2 clone, Millipore, St Charles, MO, USA). Inter- and intra-assay coefficient of variation $(\mathrm{CV})$ values for HPLC separation and IGF1 RIA of a non-pregnant female QC human plasma pool were $<19$ and $<14 \%$ respectively (14 assays). Inter- and intra-assay CV values for HPLC separation and IGF2 assays were $<15$ and $<10 \%$ respectively (13 assays).

\section{DNA extraction and genotyping}

A series of SNPs previously shown to affect circulating abundance of IGF1 (IGF1 rs1257918, IGF1 rs7965399 and $I G F 1 R$ rs2229765), circulating abundance of IGF2 (IGF2 rs680 and $H 19$ rs217727), and/or methylation of the

This work is licensed under a Creative Commons Attribution 3.0 Unported License. 
INS-IGF2-H19 locus (IGF2 rs680, IGF2 rs3741204, IGF2-AS rs1004446 and $H 19$ rs217727) were genotyped in extracted DNA. DNA was extracted from buffy coats using the X-Tractor Gene (Corbett Robotics Pty Ltd, Eight Mile Plains, QLD, Australia) following the manufacturer's instructions or by the Australian Genome Research Facility (AGRF, Adelaide, SA, Australia) using the Machery Nagel Nucleospin 96-well format. Genotyping was performed at AGRF (Brisbane, OLD, Australia) using the Sequenom MassARRAY System. The assay used the iPLEX Gold homogenous MassExtend (hME - single base extension) reaction. Oligonucleotides obtained were used to process samples in the multiplex format, then printed onto Spectro CHIPs and analysed by MALDI-TOF mass spectrometry. All genotypes were in Hardy-Weinberg equilibrium and the genotype pass rate was $>96 \%$ across all SNPs.

\section{Statistical analysis}

Statistical analyses were performed using IBM SPSS Statistics v 21. Circulating IGF concentrations were log transformed before analyses to overcome unequal variances. Effects of group (male, non-pregnant female or pregnant female) on circulating IGF concentrations were analysed by ANOVA, including age as a covariate, and groups compared using the Bonferroni's correction for multiple comparisons. In initial analyses, BMI did not alter circulating IGF concentrations when included as a covariate in univariate analyses for effects of group or when included in preliminary regression analyses (data not shown) and BMI was therefore not included as a covariate in final analyses. Effects of group on SNP frequencies were assessed by the $\chi^{2}$ analysis, or by Fisher's exact test for rare alleles. Predictors of plasma IGF concentrations were derived by stepwise backward linear regression commencing from a model including group, age, and common allele frequency for each SNP. Age was included as a covariate in models with circulating IGF1 as an outcome. For each SNP identified as significant or approaching significance $(P<0.1)$ in stepwise linear regressions, we tested the effects of SNP genotype, group and interactions on circulating IGF concentrations in two-way ANOVA and performed pair-wise cross-tabulation to determine whether these SNPs were in linkage disequilibrium.

\section{Results}

\section{Circulating IGF1 and IGF2}

Plasma IGF1 concentrations (Fig. 2A) decreased with age $(P<0.001)$ and differed between groups $(P<0.001)$. Plasma

http://www.endocrineconnections.org
$\begin{array}{lr}\text { DOI: } 10.1530 / E C-14-0068 & 2014 \text { The authors } \\ \end{array}$

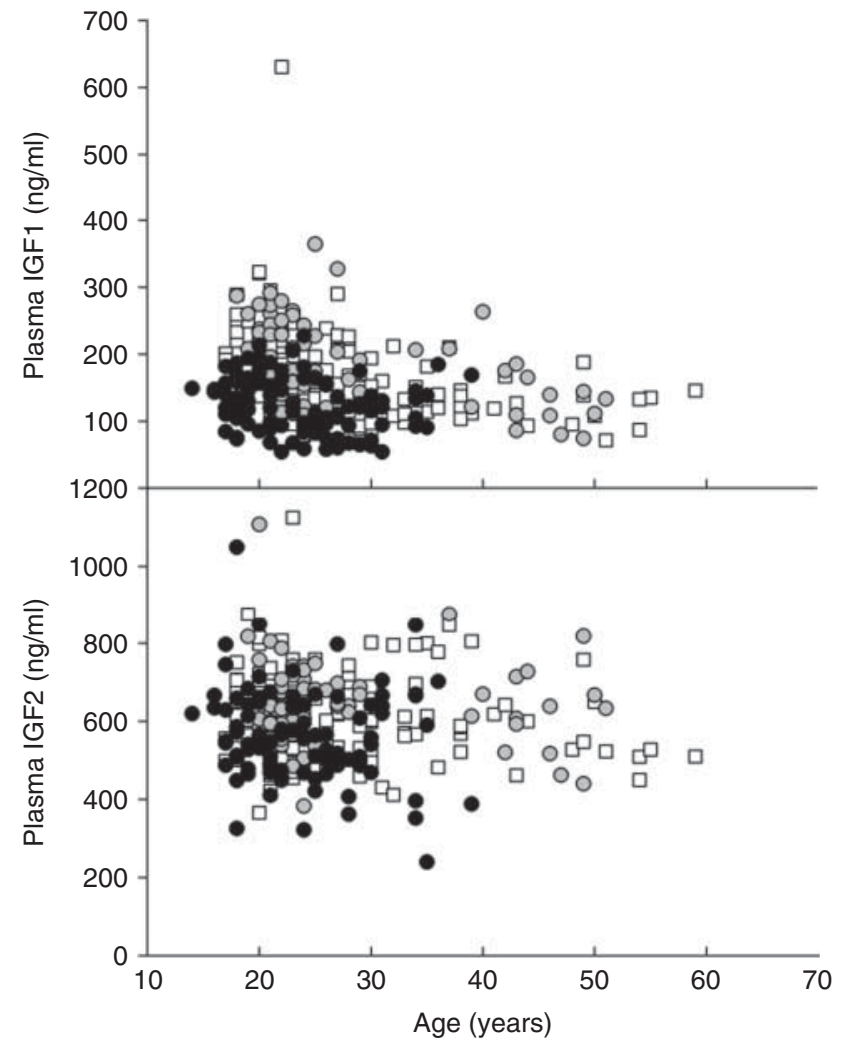

Figure 2

Circulating plasma IGF1 and IGF2 in men (white squares), non-pregnant women (grey circles) and at 15 weeks of gestation in pregnant women (black circles).

IGF1 concentrations in women at 15 weeks of gestation were 31 and $45 \%$ lower than those in men or non-pregnant women respectively $(P<0.001$ for both). Plasma IGF2 concentrations (Fig. 2B) tended to decrease with age $(P=0.078)$ and differed between groups $(P<0.001)$. Plasma IGF2 concentrations in women at 15 weeks of gestation were 9 and $12 \%$ lower than those in men or non-pregnant women respectively ( $P<0.001$ for both). Neither plasma IGF1 nor IGF2 concentrations differed between men and non-pregnant women. Effects of age on plasma IGF1 and IGF2 concentrations were similar between groups.

\section{SNP genotype frequencies}

Frequencies of individuals homozygous for the rare allele of the seven SNPs investigated varied from $18 \%$ for $I G F 1 R$ rs2229765 to 0\% for IGF1 rs12579108 and IGF1 rs7965399 (Table 2). Genotype frequencies did not differ among men, non-pregnant women and pregnant women (Table 2).

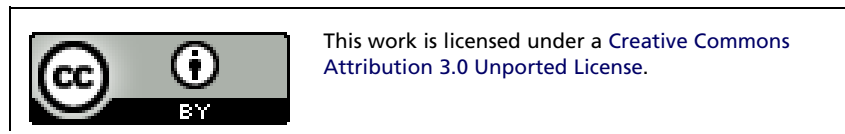


Table 2 SNP genotype frequencies.

\begin{tabular}{l}
\hline SNP and population \\
\hline IGF1 rs12579108 \\
Men \\
Non-pregnant women \\
Pregnant women \\
Total \\
IGF1 rs7965399 \\
Men \\
Non-pregnant women \\
Pregnant women \\
Total \\
IGF2 rs680 \\
Men \\
Non-pregnant women \\
Pregnant women \\
Total \\
IGF2 rs3741204 \\
Men \\
Non-pregnant women \\
Pregnant women \\
Total \\
IGF2 rs1004446 \\
Men \\
Non-pregnant women \\
Pregnant women \\
Total \\
H19 rs217727 \\
Men \\
Non-pregnant women \\
Pregnant women \\
Total \\
IGF1R rs2229765 \\
Men \\
Non-pregnant women \\
Pregnant women \\
Total \\
\hline
\end{tabular}

$+2$

CC

$130(98)$

$73(99)$

$93(96)$

$296(98)$

TT

$124(95)$

$68(92)$

$86(93)$

$278(94)$

GG

71 (56)

$39(59)$

$50(52)$

$160(55)$

AA

$54(43)$

$17(29)$

34 (37)

105 (38)

CC

58 (45)

30 (42)

36 (37)

124 (42)

CC

83 (63)

45 (62)

62 (65)

190 (64)

GG

44 (34)

25 (35)

22 (24)

91 (31)

\section{Genotype, $n(\%)$}

CA

2 (2)

1 (1)

4 (4)

7 (2)

TC

6 (5)

6 (8)

6 (7)

18 (6)

GA

48 (38)

20 (30)

44 (46)

112 (39)

AG

60 (47)

34 (58)

43 (46)

137 (49)

CT

58 (45)

32 (45)

45 (46)

135 (45)

CT

45 (34)

24 (33)

29 (31)

98 (33)

GA

65 (50)

31 (43)

$56(60)$

$152(51)$
Significance *

0.383

$0(0)$

$0(0)$

$0(0)$

$0(0)$

CC

$0(0)$

$0(0)$

$0(0)$

0 (0)

AA

8 (6)

7 (11)

2 (2)

17 (6)

GG

13 (10)

8 (14)

16 (17)

37 (14)

TT

14 (11)

9 (13)

16 (16)

39 (13)

TT

3 (2)

4 (5)

4 (4)

11 (4)

AA

22 (17)

16 (22)

15 (16)

53 (18)

* $P$ values for differences in genotype frequencies between groups were derived using the $\chi^{2}$ test, except for rare alleles (IGF1 rs12579108 and H19 rs217727), where frequencies were compared using Fisher's exact test.

\section{Effects of SNP genotype on circulating IGF1 concentrations}

In overall regression models including data from all subjects, plasma IGF1 differed between groups $(P<0.001)$, decreased with age and differed with a common allele frequency of three SNPs in the INS-IGF2H19 gene locus (Table 3). Overall, plasma IGF1 correlated positively with the numbers of the common $G$ allele of IGF2 rs680 and the common C allele of IGF2 rs1004446, and correlated negatively with the numbers of the common A allele of IGF2 rs3741204. Similar correlations of plasma IGF1 with age and SNP frequencies were observed in non-pregnant women (Table 3). Within men alone, plasma IGF1 correlated negatively with age and was

$$
\begin{array}{lr}
\text { http://www.endocrineconnections.org } & \text { ๑ } 2014 \text { The authors } \\
\text { DOI: } 10.1530 / \text { EC-14-0068 } & \text { Published by Bioscientifica Ltd }
\end{array}
$$

not correlated with the allele number for any SNP (Table 2). In pregnant women, plasma IGF1 correlated negatively with age and positively with the number of the common G allele of IGF2 rs680 (Table 3).

In separate analyses of associations of each SNP (IGF2 rs680, IGF2 rs1004446 and IGF2 rs3741204), plasma IGF1 differed between groups ( $P \leq 0.002$ for each model) and correlated negatively with subject age $(P<0.001$ for each model). Plasma IGF1 concentration differed between IGF2 rs680 genotypes, being higher in GG individuals compared with GA individuals alone $(P=0.016)$ or with GA and AA genotypes combined $(P=0.003$, Fig. 3$)$. Effects of IGF2 rs680 genotype on plasma IGF1 concentration did not differ between groups. Plasma IGF1 did not differ between IGF2 rs1004446 and IGF2 rs3741204 genotypes.

This work is licensed under a Creative Commons Attribution 3.0 Unported License. 
Table 3 Predictors of plasma IGF concentrations overall, in men, non-pregnant women and pregnant women. SNP names are shown in the form of gene names, SNP number (alleles). Correlations are partial correlations for each factor in the final model and total correlation for the model. The most common allele is shown first and the ancestral allele is underlined. Predictors of plasma hormone concentrations were derived using the natural log of plasma concentrations as outcomes by stepwise backward linear regression commencing with a model including subject group (for overall model only), age and common allele frequency for each SNP.

Groups
Plasma IGF1
Overall
Men
Non-pregnant women
Pregnant women
Plasma IGF2
Overall
Men
Pregn-pregnant women

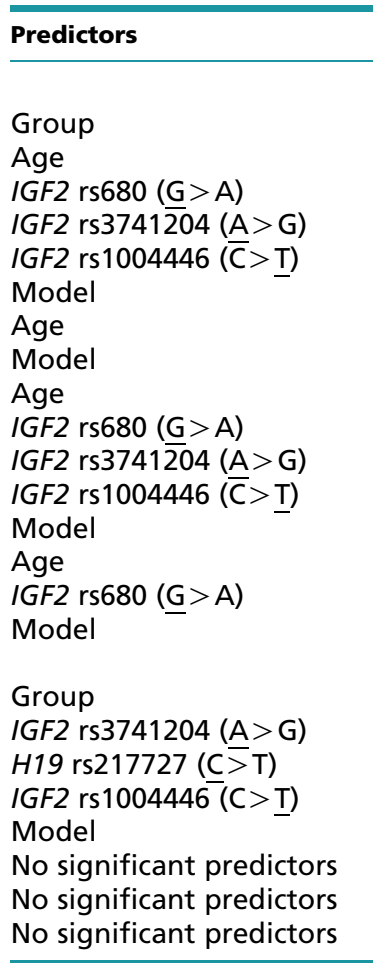

\begin{tabular}{|c|c|}
\hline$r$ & $P$ value \\
\hline-0.390 & $<0.001$ \\
\hline-0.350 & $<0.001$ \\
\hline 0.190 & 0.002 \\
\hline-0.206 & 0.001 \\
\hline 0.200 & 0.001 \\
\hline 0.501 & $<0.001$ \\
\hline-0.439 & $<0.001$ \\
\hline 0.439 & $<0.001$ \\
\hline-0.405 & 0.004 \\
\hline 0.257 & 0.074 \\
\hline-0.281 & 0.050 \\
\hline 0.246 & 0.089 \\
\hline 0.535 & 0.003 \\
\hline-0.197 & 0.068 \\
\hline 0.206 & 0.055 \\
\hline 0.289 & 0.025 \\
\hline-0.194 & 0.002 \\
\hline-0.158 & 0.010 \\
\hline-0.103 & 0.096 \\
\hline 0.153 & 0.014 \\
\hline 0.257 & 0.001 \\
\hline
\end{tabular}

\section{Effects of SNP genotype on circulating IGF2 concentrations}

Overall, plasma IGF2 concentrations differed between groups $(P=0.002)$ and with common allele numbers of three SNPs in the INS-IGF2-H19 gene locus (Table 3), but were not affected by age. Plasma IGF2 correlated positively with the number of the common $\mathrm{C}$ allele of IGF2 rs1004446 and negatively with the numbers of the common A allele of IGF2 rs3741204 and the common C allele of H19 rs217727 (Table 3). Within men alone, non-pregnant women alone, or pregnant women alone, plasma IGF2 was not correlated with allele frequencies for any SNP (Table 3).

In separate analyses of associations of each SNP with plasma IGF2, plasma IGF2 differed between groups $(P \leq 0.002$ for each model), but did not differ among IGF2 rs3741204, IGF2 rs1004446 or IGF2 rs3741204 genotypes.

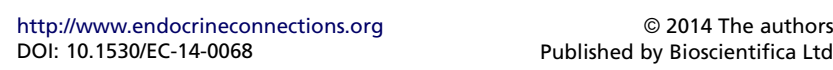

\section{Linkage analysis}

The three SNPs identified in stepwise backward regression as predictive of circulating IGF1 were in linkage disequilibrium, particularly strong between IGF2 rs3721204 and IGF2 rs1004446. Within the overall population, $97.8 \%$ of individuals $(P<0.001)$ with AA, AG and GG genotypes at IGF2 rs3721204 had CC, CT and TT genotypes, respectively, at IGF2 rs1004446, located 235 nucleotides distant within the IGF2 gene (Fig. 1). Genotype of IGF2 rs680 shared $34.4 \%$ concordance with IGF2 rs1004446 $(P=0.007)$ and $32.0 \%$ concordance with IGF2 rs3721204 $(P=0.016)$. Two of the three SNPs identified in stepwise backward regression as predictive of circulating IGF2 were in linkage disequilibrium, IGF2 rs3721204 and IGF2 rs1004446, as described above. Genotype at H19 rs217727 tended towards concordance with IGF2 rs1004446 genotype $(P=0.053)$ but not with IGF2 rs3721204 genotype.

This work is licensed under a Creative Commons Attribution 3.0 Unported License. 


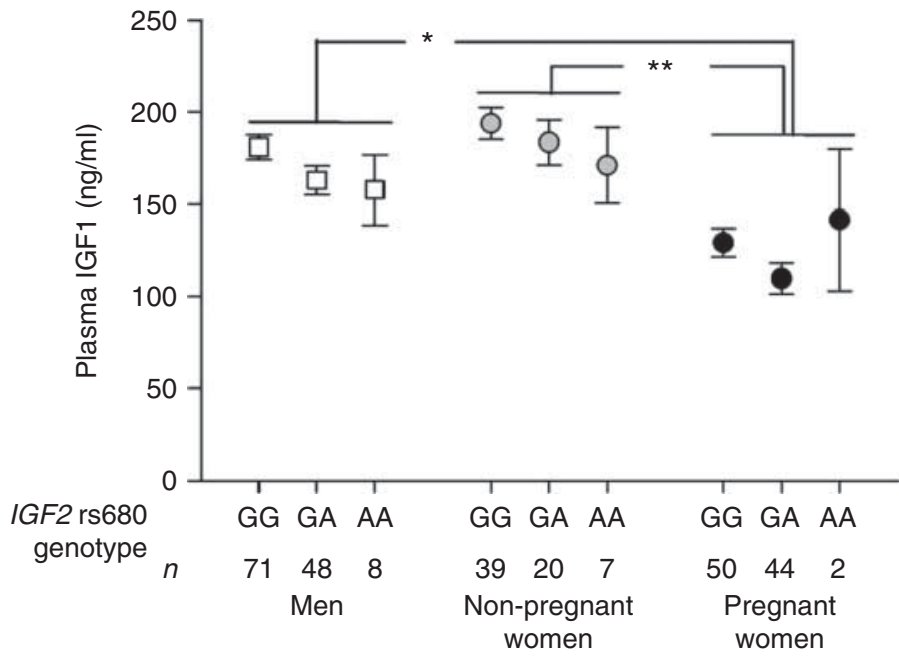

Age, $P<0.001$

Group, $P=0.002$

Genotype, $P=0.020$

Group $\times$ genotype, $P>0.6$

$\mathrm{GG}>\mathrm{GA}, P=0.016$

$\mathrm{GG}>\mathrm{GA}+\mathrm{AA}, P=0.003$

\section{Figure 3}

Plasma IGF1 according to IGF2 rs680 SNP genotype in men (white squares), non-pregnant women (grey circles) and at 15 weeks of gestation in pregnant women (black circles). Plasma IGF1 data are estimated means and
S.E.M. adjusted to an average age of 26.2 years. Differences between groups are indicated as follows: ${ }^{*} P<0.05 ; * * P<0.01$.

populations. This is the first report of lower circulating IGF1 concentration in pregnant women with the A allele at IGF2 rs680 SNP genotype. Given the endocrine actions of maternal IGFs in pregnancy, we hypothesise that IGF2 rs680 genotype may affect placental development and function and maternal adaptation to pregnancy. We are currently exploring these effects in women who experienced pregnancy complications in a separate study.

Circulating IGF1 concentrations were lower in women at 15 weeks of gestation than in either men or nonpregnant women in this study. Our data, obtained using a methodology that completely separates IGFs from IGFBPs before assay and prevents IGFBP interference in IGF assays, are consistent with previous reports of reductions in circulating IGF1 during early-mid pregnancy from longitudinal studies $(14,15)$. We hypothesise that this decrease of $\sim 45 \%$ in circulating IGF1 at 15 weeks of gestation, compared with non-pregnant women, largely reflects increased negative feedback on IGF1 production, due to increased IGF1 bioavailability despite reduced total IGF1 concentrations. Proteolysis of IGFBP3 and other IGFBPs increases rapidly in human pregnancy by $\sim 6-8$ weeks of gestation and decreases their binding affinity for IGFs, which increases circulating concentrations of free or unbound IGFs available to bind receptors $(58,59,60)$. The placenta produces two metalloproteinases which proteolyse IGFBPs: pregnancy-associated plasma protein A (PAPPA), which cleaves IGFBP4 and to a lesser extent requires confirmation in additional independent

http://www.endocrineconnections.org DOI: 10.1530/EC-14-0068
(C) 2014 The authors Published by Bioscientifica Ltd
This work is licensed under a Creative Commons Attribution 3.0 Unported License. 
IGFBP5 (reviewed by (61)), and PAPPA2, which mostly cleaves IGFBP5 (62). Haemodilution, due to expansion of maternal blood volume in early pregnancy, may also account for $\sim 20-25 \%$ of the fall in circulating IGF1 concentration that we observed (14).

The increases in circulating IGF1 concentration reported in later pregnancy $(8,9,11,14,16)$ are probably a response to increasing maternal circulating GH concentrations stimulated by rapid increases in placental $\mathrm{GH}$ production during the second trimester (63). These result in elevated, non-pulsatile GH concentration in maternal circulation from 17-24 weeks of gestation $(63,64)$. Plasma IGF1 and IGF2 normalise across gestation in women who are deficient in pituitary GH (65), implying that placental GH is a major regulator of IGF abundance during pregnancy. Furthermore, the human placenta itself expresses IGF1 and $I G F 2$, and IGF1 gene and protein expression occurs on both maternal and foetal sides of the human placenta $(66,67)$, and placental tissues might therefore be a source of circulating IGFs during pregnancy. This study is the first to show that IGF1 falls with age in pregnant women, while the decrease with age in non-pregnant women is consistent with previous reports that IGF1 falls from young to old adulthood (4). Plasma IGF1 did not differ between nonpregnant women and men, consistent with most previous studies, where although the pattern of change in circulating IGF1 throughout puberty differed between sexes, plasma concentrations are similar in men and women as young and old adults $(2,4)$. Small sex differences were evident in a recent multi-centre study with over 15000 subjects, where circulating IGF1 concentrations were slightly lower in women than men (5).

The 12\% lower IGF2 concentration in pregnant women at 15 weeks of gestation compared with nonpregnant women at similar ages is consistent with the magnitude of reductions in circulating IGF2 at similar stages of pregnancy reported previously in longitudinal studies $(14,15)$. This early-pregnancy fall in IGF2 was explained by haemodilution (14) due to expansion of maternal blood volume in early pregnancy. Our findings across the adult age range in this study extend those from studies in children throughout puberty and up to young adulthood $(6,7)$, where plasma IGF2 concentrations also do not change with age or differ between sexes.

Our results provide the first evidence that SNP genotypes in the INS-IGF2-H19 locus associate with circulating concentrations of IGF1, as well as IGF2. The number of IGF2 rs680 common G alleles was positively associated with circulating IGF1 concentrations overall and in non-pregnant and pregnant women analysed separately. Associations of genotypes at this SNP with circulating IGF1 were robust and did not differ among men, non-pregnant or pregnant women in univariate analysis. In this study, individuals with the IGF2 rs680 GA or GA + AA genotypes consistently had lower plasma IGF1 concentrations than those homozygous for the $G$ allele. The $G$ allele has previously been associated with lower circulating IGF2 concentrations than the A allele in middle-aged men (42), but we did not find any association between genotype at this SNP and plasma IGF2 in this study. This suggests that associations between IGF2 rs680 and circulating IGF1 do not reflect competition with circulating IGF2 for IGFBP-binding sites and consequent effects on circulating half-life. IGF2 is imprinted and only the paternally inherited allele is expressed in many, but not all, tissues postnatally (37). Differences in circulating IGF1 between GG and GA + AA genotypes observed in this study are therefore likely to be smaller than the actual effects of the paternally expressed alleles of IGF2 rs680, as the GA heterozygotes will include individuals with paternally inherited A and G alleles. As these three SNPs in IGF2 were in linkage disequilibrium within this population, associations of circulating IGF1 with IGF2 rs680 SNP genotype could reflect variation anywhere within this region. Nevertheless, they do suggest that genotypes at this locus might affect placental development and maternal adaptation to pregnancy via effects on IGF1 or IGF2 abundance, given that both these peptides are endocrine regulators of placental growth and differentiation (17). Further studies are needed to confirm these effects of INS-IGF2-H19 locus SNP genotypes on circulating IGF1, to investigate underlying mechanisms and assess potential effects on the placenta and mother.

Across all groups combined $(n=307)$, SNP genotype at IGF2 rs3741204, H19 rs217727 and IGF2 rs1004446 correlated with circulating plasma IGF2 in multiple linear regression analyses. A negative association of the common C allele of H19 rs217727 with circulating IGF2 concentrations is consistent with the reported effects of this SNP on cord blood IGF2 (52). This study provides the first evidence that SNP genotype at IGF2 rs3741204 or IGF2 rs1004446 may affect circulating IGF2. Genotypes at these two SNPs were extremely tightly linked in this population, consistent with their proximity within the IGF2 and IGF2-AS genes at 235 nucleotides apart. These associations might therefore reflect effects of either of these SNPs or of other SNPs in this linkage region. Our findings, together with previously reported associations between IGF2 rs680 genotype and circulating IGF2 in one study of middleaged men (42), are also consistent with the hypothesis that

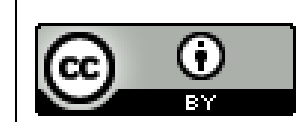

This work is licensed under a Creative Commons Attribution 3.0 Unported License. 
SNPs that are associated with altered methylation of the INS-IGF2-H19 locus, such as IGF2 rs3741204, IGF2 rs1004446 and IGF2 rs680 (41, 53), may affect IGF2 expression and secretion. Further investigations are required to identify which SNP or SNPs in this region alter(s) the methylation and expression of IGF2. The loss of associations of any SNPs with circulating IGF2 in men $(n=134)$, non-pregnant women $(n=74)$ or pregnant women $(n=98)$ in regression models run separately in each group, or when analysing effects of genotype and group separately for each SNP, probably reflects the limited power due to smaller sample sizes within each sub-group of this study. Comparing effects of these three SNPs between sexes and in pregnant and non-pregnant populations will require additional, larger studies.

In conclusion, plasma IGF1 and IGF2 concentrations were lower in pregnant women at 15 weeks of gestation than in men or non-pregnant women and did not differ between adult men and non-pregnant women. We have identified SNPs in the INS-IGF2-H19 locus associated with circulating IGF1, as well as IGF2. Associations between IGF2 rs680 and circulating IGF1 did not differ among men, non-pregnant and pregnant women. As maternal circulating IGFs in early-mid pregnancy are endocrine regulators of placental development and function, these genotypes may also predict foetal growth and risk for pregnancy complications. Further studies are needed to confirm these putative effects of SNPs in the INS-IGF2-H19 locus on circulating IGF1 and IGF2 concentrations and identify the underlying mechanisms.

\section{Declaration of interest}

The authors declare that there is no conflict of interest that could be perceived as prejudicing the impartiality of the research reported.

\section{Funding}

This work was supported by a grant from the Premier's Science and Research Fund in South Australia (awarded to C T Roberts and G A Dekker) and by the National Health and Medical Research Council of Australia (NHMRC) Project grant 519225 awarded to C T Roberts and G A Dekker. C T Roberts was supported by a NHMRC Senior Research Fellowship (APP1020749). $S$ Buckberry was supported by an Australian Postgraduate Award and Healthy Development Adelaide and Channel 7 Children's Research Foundation PhD Scholarship. The sponsors had no role in study design, data analysis or interpretation or the decision to submit the manuscript.

\section{Author contribution statement}

K L Gatford, J A Owens, C T Roberts and G A Dekker conceived and designed the research project. K L Gatford, G K Heinemann, S D Thompson and J V Zhang performed sample and data analysis. K L Gatford and
C T Roberts drafted the manuscript. All authors contributed to critical revision and approved the final draft of the manuscript.

\section{Acknowledgements}

The authors thank all of the subjects who participated in these studies. This work included samples collected in Adelaide, Australia, by the SCOPE consortium, and we thank Denise Healy for coordinating the Adelaide cohort. They also thank MedSciNet (Sweden), Eliza Chan and SCOPE midwives for their support with the SCOPE database.

\section{References}

1 Yu H, Mistry J, Nicar MJ, Khosravi MJ, Diamandis A, van Doorn J \& Juul A Insulin-like growth factors (IGF-I, free IGF-I, and IGF-II) and insulin-like growth factor binding proteins (IGFBP-2, IGFBP-3, IGFBP-6, and ALS) in blood circulation. Journal of Clinical Laboratory Analysis 199913 166-172. (doi:10.1002/(SICI)1098-2825(1999)13:4<166::AID-JCLA5 > 3.0.CO;2-X)

2 Juul A, Bang P, Hertel N, Main K, Dalgaard P, Jorgensen K, Muller J, Hall K \& Skakkebaek N. Serum insulin-like growth factor-I in 1030 healthy children, adolescents, and adults: relation to age, sex, stage of puberty, testicular size, and body mass index. Journal of Clinical Endocrinology and Metabolism 199478 744-752. (doi:10.1210/jcem.78. 3.8126152)

3 Brabant G, von zur Mühlen A, Wüster C, Ranke MB, Kratzsch J, Kiess W, Ketelslegers JM, Wilhelmsen L, Hulthén L, Saller B et al. Serum insulin-like growth factor I reference values for an automated chemiluminescence immunoassay system: results from a multicenter study. Hormone Research in Paediatrics 200360 53-60. (doi:10.1159/000071871)

4 Yamamoto H, Sohmiya M, Oka N \& Kato Y. Effects of aging and sex on plasma insulin-like growth factor I (IGF-I) levels in normal adults. Acta Endocrinologica 1991124 497-500.

5 Bidlingmaier M, Friedrich N, Emeny RT, Spranger J, Wolthers OD, Roswall J, Korner A, Obermayer-Pietsch B, Hubener C, Dahlgren J et al. Reference intervals for insulin-like growth factor-1 (IGF-I) from birth to senescence: results from a multicenter study using a new automated chemiluminescence IGF-I immunoassay conforming to recent international recommendations. Journal of Clinical Endocrinology and Metabolism 201499 1712-1721. (doi:10.1210/jc.2013-3059)

6 Merimee TJ, Zapf J, Hewlett B \& Cavalli-Sforza LL. Insulin-like growth factors in pygmies. The role of puberty in determining final stature. New England Journal of Medicine 1987316 906-911. (doi:10.1056/ NEJM198704093161503)

7 Juul A, Dalgaard P, Blum WF, Bang P, Hall K, Michaelsen KF, Muller J \& Skakkebaek NE. Serum levels of insulin-like growth factor (IGF)-binding protein-3 (IGFBP-3) in healthy infants, children, and adolescents: the relation to IGF-I, IGF-II, IGFBP-1, IGFBP-2, age, sex, body mass index, and pubertal maturation. Journal of Clinical Endocrinology and Metabolism 199580 2534-2542. (doi:10.1210/jcem.80.8.7543116)

8 Gargosky SE, Moyse KJ, Walton PE, Owens JA, Wallace JC, Robinson JS $\&$ Owens PC. Circulating levels of insulin-like growth factors increase and molecular forms of their serum binding proteins change with human pregnancy. Biochemical and Biophysical Research Communications 1990170 1157-1163. (doi:10.1016/0006-291X(90)90514-N)

9 Hills FA, English J \& Chard T. Circulating levels of IGF-I and IGF-binding protein-1 throughout pregnancy: relation to birthweight and maternal weight. Journal of Endocrinology 1996148 303-309. (doi:10.1677/joe.0.1480303)

10 Wilson DM, Bennett A, Adamson GD, Nagashima RJ, Liu F, DeNatale ML, Hintz RL \& Rosenfeld RG. Somatomedins in pregnancy: a cross-sectional study of insulin-like growth factors I and II and somatomedin peptide content in normal human pregnancies. Journal of Clinical Endocrinology and Metabolism 198255 858-861. (doi:10.1210/jcem-55-5-858)

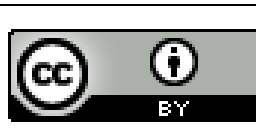


11 Mirlesse V, Frankenne F, Alsat E, Poncelet M, Hennen G \& Evain-Brion D. Placental growth hormone levels in normal pregnancy and in pregnancies with intrauterine growth retardation. Pediatric Research 199334 439-442. (doi:10.1203/00006450-199310000-00011)

12 Naylor KE, Iqbal P, Fledelius C, Fraser RB \& Eastell R. The effect of pregnancy on bone density and bone turnover. Journal of Bone and Mineral Research 200015 129-137. (doi:10.1359/jbmr.2000.15.1.129)

13 Black AJ, Topping J, Durham B, Farquharson RG \& Fraser WD. A detailed assessment of alterations in bone turnover, calcium homeostasis, and bone density in normal pregnancy. Journal of Bone and Mineral Research 200015 557-563. (doi:10.1359/jbmr.2000.15.3.557)

14 Monaghan JM, Godber IM, Lawson N, Kaur M, Wark G, Teale D \& Hosking DJ. Longitudinal changes of insulin-like growth factors and their binding proteins throughout normal pregnancy. Annals of Clinical Biochemistry 200441 220-226. (doi:10.1258/000456304323019596)

15 Olausson H, Lof M, Brismar K, Lewitt M, Forsum E \& Sohlstrom A. Longitudinal study of the maternal insulin-like growth factor system before, during and after pregnancy in relation to fetal and infant weight. Hormone Research 200869 99-106. (doi:10.1159/000111813)

16 Sowers M, Scholl T, Grewal J, Chen X \& Jannausch M. IGF-I, osteocalcin, and bone change in pregnant normotensive and pre-eclamptic women. Journal of Clinical Endocrinology and Metabolism 200186 5898-5903. (doi:10.1210/jcem.86.12.8114)

17 Sferruzzi-Perri AN, Owens JA, Pringle KG \& Roberts CT. The neglected role of insulin-like growth factors in the maternal circulation regulating fetal growth. Journal of Physiology 2011589 7-20. (doi:10.1113/ jphysiol.2010.198622)

18 Sferruzzi-Perri AN, Owens JA, Pringle KG, Robinson JS \& Roberts CT. Maternal insulin-like growth factors-I and -II act via different pathways to promote fetal growth. Endocrinology 2006147 3344-3355. (doi:10.1210/en.2005-1328)

19 Sferruzzi-Perri AN, Owens JA, Standen P, Taylor RL, Heinemann GK, Robinson JS \& Roberts CT. Early treatment of the pregnant guinea pig with IGFs promotes placental transport and nutrient partitioning near term. American Journal of Physiology 2007292 E668-E676. (doi:10.1152/ajpendo.00320.2006)

20 Sferruzzi-Perri AN, Owens JA, Standen P, Taylor RL, Robinson JS \& Roberts CT. Early pregnancy maternal endocrine insulin-like growth factor I programs the placenta for increased functional capacity throughout gestation. Endocrinology 2007148 4362-4370. (doi:10.1210/en.2007-0411)

21 McIntyre HD, Serek R, Crane DI, Veveris-Lowe T, Parry A, Johnson S, Leung KC, Ho KK, Bougoussa M, Hennen Getal. Placental growth hormone (GH), GH-binding protein, and insulin-like growth factor axis in normal, growth-retarded, and diabetic pregnancies: correlations with fetal growth. Journal of Clinical Endocrinology and Metabolism 200085 1143-1150.

22 Vella A, Bouatia-Naji N, Heude B, Cooper J, Lowe C, Petry C, Ring S, Dunger D, Todd J \& Ong K. Association analysis of the IGF1 gene with childhood growth, IGF-1 concentrations and type 1 diabetes. Diabetologia 200851 811-815. (doi:10.1007/s00125-008-0970-7)

23 Hernandez W, Grenade C, Santos ER, Bonilla C, Ahaghotu C \& Kittles RA. IGF-1 and IGFBP-3 gene variants influence on serum levels and prostate cancer risk in African-Americans. Carcinogenesis 200728 2154-2159. (doi:10.1093/carcin/bgm190)

24 Patel AV, Cheng I, Canzian F, Le Marchand L, Thun MJ, Berg CD, Buring J, Calle EE, Chanock S, Clavel-Chapelon F et al. IGF-1, IGFBP-1, and IGFBP-3 polymorphisms predict circulating IGF levels but not breast cancer risk: findings from the breast and prostate cancer cohort consortium (BPC3). PLoS ONE 20083 e2578. (doi:10.1371/journal.pone.0002578)

25 Su X, Colditz GA, Willett WC, Collins LC, Schnitt SJ, Connolly JL, Pollak MN, Rosner B \& Tamimi RM. Genetic variation and circulating levels of IGF-I and IGFBP-3 in relation to risk of proliferative benign breast disease. International Journal of Cancer 2010126 180-190. (doi:10.1002/ijc.24674)

26 Qian B, Zheng H, Yu H \& Chen K. Genotypes and phenotypes of IGF-I and IGFBP-3 in breast tumors among Chinese women. Breast Cancer
Research and Treatment 2011130 217-226. (doi:10.1007/s10549-0111552-9)

27 de Alencar SA \& Lopes JCD. A comprehensive in silico analysis of the functional and structural impact of SNPs in the IGF1R gene. Journal of Biomedicine \& Biotechnology 20102010 Article ID 715139. (doi:10.1155/2010/715139)

28 Bonafe M, Barbieri M, Marchegiani F, Olivieri F, Ragno E, Giampieri C, Mugianesi E, Centurelli M, Franceschi C \& Paolisso G. Polymorphic variants of insulin-like growth factor I (IGF-I) receptor and phosphoinositide 3-kinase genes affect IGF-I plasma levels and human longevity: cues for an evolutionarily conserved mechanism of life span control. Journal of Clinical Endocrinology and Metabolism 200388 3299-3304. (doi:10.1210/jc.2002-021810)

29 Albani D, Batelli S, Polito L, Vittori A, Pesaresi M, Gajo G, De Angeli S, Zanardo A, Gallucci M \& Forloni G. A polymorphic variant of the insulin-like growth factor 1 (IGF-1) receptor correlates with male longevity in the Italian population: a genetic study and evaluation of circulating IGF-1 from the "Treviso Longeva (TRELONG)" study. BMC Geriatrics 20099 19. (doi:10.1186/1471-2318-9-19)

30 Albani D, Mazzuco S, Polito L, Batelli S, Biella G, Ongaro F, Gustafson DR, Antuono P, Gajo G, Durante E et al. Insulin-like growth factor 1 receptor polymorphism rs 2229765 and circulating interleukin6 level affect male longevity in a population-based prospective study (Treviso Longeva - TRELONG). Aging Male 201114 257-264. (doi:10.3109/13685538.2011.607521)

31 Biong M, Gram I, Brill I, Johansen F, Solvang H, Alnaes G, Fagerheim T, Bremnes Y, Chanock S, Burdett L et al. Genotypes and haplotypes in the insulin-like growth factors, their receptors and binding proteins in relation to plasma metabolic levels and mammographic density. BMC Medical Genomics 20103 9. (doi:10.1186/1755-8794-3-9)

32 Stanilova S, Ivanova M, Karakolev I, Stoilov R, Rashkov R \& Manolova I. Association of $+3179 \mathrm{G} / \mathrm{A}$ insulin-like growth factor-1 receptor polymorphism and insulin-like growth factor-1 serum level with systemic lupus erythematosus. Lupus 201322 1388-1393. (doi:10.1177/0961203313502860)

33 Chia VM, Sakoda LC, Graubard BI, Rubertone MV, Chanock SJ, Erickson RL \& McGlynn KA. Risk of testicular germ cell tumors and polymorphisms in the insulin-like growth factor genes. Cancer Epidemiology, Biomarkers \& Prevention 200817 721-726. (doi:10.1158/ 1055-9965.EPI-07-0768)

34 Laron Z. Natural history of the classical form of primary growth hormone $(\mathrm{GH})$ resistance (Laron syndrome). Journal of Pediatric Endocrinology \& Metabolism 199912 231-249.

35 Laron Z. The GH-IGF1 axis and longevity. The paradigm of IGF1 deficiency. Hormones 20087 24-27. (doi:10.14310/horm.2002.1111034)

36 Ekstrom TJ, Cui H, Li X \& Ohlsson R. Promoter-specific IGF2 imprinting status and its plasticity during human liver development. Development 1995121 309-316.

37 Wu H-K, Squire JA, Song Q \& Weksberg R. Promoter-dependent tissue-specific expressive nature of imprinting gene, insulin-like growth factor II, in human tissues. Biochemical and Biophysical Research Communications 1997233 221-226. (doi:10.1006/bbrc. 1997.6431)

38 Monk D, Sanches R, Arnaud P, Apostolidou S, Hills FA, Abu-Amero S, Murrell A, Friess H, Reik W, Stanier P et al. Imprinting of IGF2 P0 transcript and novel alternatively spliced INS-IGF2 isoforms show differences between mouse and human. Human Molecular Genetics 2006 15 1259-1269. (doi:10.1093/hmg/ddl041)

39 Buckberry S, Bianco-Miotto T, Hiendleder S \& Roberts CT. Quantitative allele-specific expression and DNA methylation analysis of H19, IGF2 and IGF2R in the human placenta across gestation reveals H19 imprinting plasticity. PLOS ONE 20127 e51210. (doi:10.1371/journal. pone.0051210)

40 Maher ER \& Reik W. Beckwith-Wiedemann syndrome: imprinting in clusters revisited. Journal of Clinical Investigation 2000105 247-252. (doi:10.1172/JCI9340)

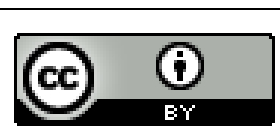


41 Heijmans BT, Kremer D, Tobi EW, Boomsma DI \& Slagboom PE. Heritable rather than age-related environmental and stochastic factors dominate variation in DNA methylation of the human IGF2/H19 locus. Human Molecular Genetics 2007 16 547-554. (doi:10.1093/hmg/ddm010)

42 O'Dell SD, Miller GJ, Cooper JA, Hindmarsh PC, Pringle PJ, Ford H, Humphries SE \& Day INM. Apal polymorphism in insulin-like growth factor II (IGF2) gene and weight in middle-aged males. International Journal of Obesity and Related Metabolic Disorders 199721 822-825. (doi:10.1038/sj.ijo.0800483)

43 Petry CJ, Seear RV, Wingate DL, Manico L, Acerini CL, Ong KK, Hughes IA \& Dunger DB. Associations between paternally transmitted fetal IGF2 variants and maternal circulating glucose concentrations in pregnancy. Diabetes 201160 3090-3096. (doi:10.2337/db11-0689)

44 Roth SM, Schrager MA, Metter EJ, Riechman SE, Fleg JL, Hurley BF \& Ferrell RE. IGF2 genotype and obesity in men and women across the adult age span. International Journal of Obesity and Related Metabolic Disorders 200226 585-587. (doi:10.1038/sj.ijo.0801927)

45 Sayer AA, Syddall H, O'Dell SD, Chen XH, Briggs PJ, Briggs R, Day IN \& Cooper C. Polymorphism of the IGF2 gene, birth weight and grip strength in adult men. Age and Ageing 200231 468-470. (doi:10.1093/ ageing/31.6.468)

46 Keku T, Vidal A, Oliver S, Hoyo C, Hall I, Omofoye O, McDoom M, Worley K, Galanko J, Sandler R et al. Genetic variants in IGF-I, IGF-II, IGFBP-3, and adiponectin genes and colon cancer risk in African Americans and Whites. Cancer Causes \& Control 201223 1127-1138. (doi:10.1007/s10552-012-9981-2)

47 Vafiadis P, Bennett ST, Todd JA, Grabs R \& Polychronakos C. Divergence between genetic determinants of IGF2 transcription levels in leukocytes and of IDDM2-encoded susceptibility to type 1 diabetes. Journal of Clinical Endocrinology and Metabolism $1998 \mathbf{8 3}$ 2933-2939. (doi:10.1210/jcem.83.8.5048)

48 Gomes MVM, Soares MR, Pasqualim-Neto A, Marcondes CR, Lôbo RB \& Ramos ES. Association between birth weight, body mass index and IGF2/ApaI polymorphism. Growth Hormone \& IGF Research 200515 360-362. (doi:10.1016/j.ghir.2005.06.016)

49 Kaku K, Osada H, Seki K \& Sekiya S. Insulin-like growth factor 2 (IGF2) and IGF2 receptor gene variants are associated with fetal growth. Acta Paediatrica 200796 363-367. (doi:10.1111/j.1651-2227.2006.00120.x)

50 Adkins RM, Somes G, Morrison JC, Hill JB, Watson EM, Magann EF \& Krushkal J. Association of birth weight with polymorphisms in the IGF2, H19, and IGF2R genes. Pediatric Research 201068 429-434. (doi:10.1203/PDR.0b013e3181f1ca99)

51 Heude B, Ong KK, Luben R, Wareham NJ \& Sandhu MS. Study of association between common variation in the insulin-like growth factor 2 gene and indices of obesity and body size in middle-aged men and women. Journal of Clinical Endocrinology and Metabolism 200792 2734-2738. (doi:10.1210/jc.2006-1948)

52 Petry C, Ong K, Barratt B, Wingate D, Cordell H, Ring S, Pembrey M, Team TAS, Reik W, Todd J et al. Common polymorphism in H19 associated with birthweight and cord blood IGF-II levels in humans. BMC Genetics 20056 22. (doi:10.1186/1471-2156-6-22)

53 Murrell A, Heeson S, Cooper WN, Douglas E, Apostolidou S, Moore GE, Maher ER \& Reik W. An association between variants in the IGF2 gene and Beckwith-Wiedemann syndrome: interaction between genotype and epigenotype. Human Molecular Genetics 200413 247-255. (doi:10.1093/hmg/ddh013)

54 Kho EM, McCowan LME, North RA, Roberts CT, Chan E, Black MA, Taylor RS \& Dekker GA. Duration of sexual relationship and its effect on preeclampsia and small for gestational age perinatal outcome. Journal of Reproductive Immunology 200982 66-73. (doi:10.1016/j.jri.2009.04.011)
55 Sykes SD, Pringle KG, Zhou A, Dekker GA, Roberts CT, Lumbers ER \& Consortium $S$. Fetal sex and the circulating renin-angiotensin system during early gestation in women who later develop preeclampsia or gestational hypertension. Journal of Human Hypertension 201428 133-139. (doi:10.1038/jhh.2013.51)

56 Owens PC, Johnson RJ, Campbell RG \& Ballard FJ. Growth hormone increases insulin-like growth factor (IGF-I) and decreases IGF-II in plasma of growing pigs. Journal of Endocrinology 1990124 269-275. (doi:10.1677/joe.0.1240269)

57 Carr JM, Owens JA, Grant PA, Walton PE, Owens PC \& Wallace JC. Circulating insulin-like growth factors (IGFs), IGF-binding proteins (IGFBPs) and tissue mRNA levels of IGFBP-2 and IGFBP-4 in the ovine fetus. Journal of Endocrinology 1995145 545-557. (doi:10.1677/joe.0.1450545)

58 Giudice LC, Farrell EM, Pham H, Lamson G \& Rosenfeld RG. Insulinlike growth factor binding proteins in maternal serum throughout gestation and in the puerperium: effects of a pregnancy-associated serum protease activity. Journal of Clinical Endocrinology and Metabolism 199071 806-816. (doi:10.1210/jcem-71-4-806)

59 Hossenlopp P, Segovia B, Lassarre C, Roghani M, Bredon M \& Binoux M. Evidence of enzymatic degradation of insulin-like growth factorbinding proteins in the $150 \mathrm{~K}$ complex during pregnancy. Journal of Clinical Endocrinology and Metabolism 199071 797-805. (doi:10.1210/ jcem-71-4-797)

60 Hasegawa T, Hasegawa Y, Takada M \& Tsuchiya Y. The free form of insulin-like growth factor I increases in circulation during normal human pregnancy. Journal of Clinical Endocrinology and Metabolism 1995 80 3284-3286. (doi:10.1210/jcem.80.11.7593439)

61 Boldt HB \& Conover CA. Pregnancy-associated plasma protein-A (PAPP-A): a local regulator of IGF bioavailability through cleavage of IGFBPs. Growth Hormone \& IGF Research 200717 10-18. (doi:10.1016/j. ghir.2006.11.003)

62 Yan X, Baxter RC \& Firth SM. Involvement of pregnancy-associated plasma protein-A2 in insulin-like growth factor (IGF) binding protein-5 proteolysis during pregnancy: a potential mechanism for increasing IGF bioavailability. Journal of Clinical Endocrinology and Metabolism 2010 95 1412-1420. (doi:10.1210/jc.2009-2277)

63 Eriksson L, Frankenne F, Eden S, Hennen G \& Vonschoultz B. Growth-hormone secretory profiles in pregnancy - lack of pulsatility for the secretion of the placental variant. British Journal of Obstetrics and Gynaecology 198996 949-953. (doi:10.1111/j.1471-0528.1989. tb03352.x)

64 Frankenne F, Closset J, Gomez F, Scippo M, Smal J \& Hennen G. The physiology of growth hormones (GHs) in pregnant women and partial characterisation of the placental GH variant. Journal of Clinical Endocrinology and Metabolism 198866 1171-1180. (doi:10.1210/jcem-66-6-1171)

65 Hall K, Enberg G, Hellem E, Lundin G, Ottosson-Seeberger A, Sara V, Trygstad O \& Öfverholm U. Somatomedin levels in pregnancy: longitudinal study in healthy subjects and patients with growth hormone deficiency. Journal of Clinical Endocrinology and Metabolism 198459 587-594. (doi:10.1210/jcem-59-4-587)

66 Han VK, Bassett N, Walton J \& Challis JR. The expression of insulin-like growth factor (IGF) and IGF-binding protein (IGFBP) genes in the human placenta and membranes: evidence for IGF-IGFBP interactions at the feto-maternal interface. Journal of Clinical Endocrinology and Metabolism 199681 2680-2693. (doi:10.1210/jcem.81.7.8675597)

67 Iñiguez G, González CA, Argandoña F, Kakarieka E, Johnson MC \& Cassorla F. Expression and protein content of IGF-I and IGF-I receptor in placentas from small, adequate and large for gestational age newborns. Hormone Research in Paediatrics 201073 320-327. (doi:10.1159/000308163)
Received in final form 10 August 2014

Accepted 12 August 2014

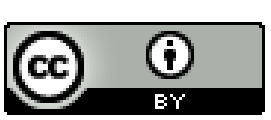

This work is licensed under a Creative Commons Attribution 3.0 Unported License. 